\title{
Strategies for Involving Parents in School Communication and Application in a K-1 Special Education System
}

\author{
Mindy Kim \\ Special Education, Drexel University, Philadelphia, USA \\ Email: kimmindy7@gmail.com
}

How to cite this paper: Kim, M. (2017). Strategies for Involving Parents in School Communication and Application in a $\mathrm{K}-1$ Special Education System. Creative Education, 8, 765-787.

https://doi.org/10.4236/ce.2017.86057

Received: December 20, 2016

Accepted: May 9, 2017

Published: May 12, 2017

Copyright $\odot 2017$ by author and Scientific Research Publishing Inc. This work is licensed under the Creative Commons Attribution International License (CC BY 4.0).

http://creativecommons.org/licenses/by/4.0/

\section{(c) (i) Open Access}

\begin{abstract}
This study aimed to determine practices that could improve communication and participation in special education classrooms with parents. Special education classrooms seem to have greater difficulty cultivating relationships with parents due to the complex nature of education. Improved communication has shown that it can have a positive effect on student achievement as well as communication between parents, teachers, and schools. The classroom was made up of all special education students that ranged in grades $\mathrm{k}-1$, male/female, and variation of intellectual disabilities. The school is located near a military base and situated in an area that has higher rates of poverty. Indirect methods of communication were utilized in this study; classroom newsletters, daily communication chart with weekly feedback, and a parent questionnaire. The action research showed that there was some improvement in perceptions of positive interactions as well as a steady rate of participation using indirect methods of communication. Indirect methods seemed to provide some improvements in communication between parents, teachers, and schools. It showed that most parents had an improved perception of the teacher and were mostly satisfied with the communication. Future research could look at other indirect methods of communication, direct forms of communication, or a combination of both.
\end{abstract}

\section{Keywords}

Special Education, Communication, Family, School, Teacher

\section{Introduction}

Student success not only takes place in the classroom but at home as well. With changes in testing, rigorous curriculums, and more demands placed on students. 
It is becoming more apparent, one short fall of education is the lack of parent involvement in schools. The community is diverse, with military families and low income families making up most of the school's population. The goal of this study is to use three strategies to see if parent involvement will increase, their attitudes toward the school and teacher improve, and if they feel a part of their child's education. The strategies will try to serve diverse needs by using indirect and direct forms of communication along with in person activities that will be chosen by the parents. Normally, activities are chosen and parents get to choose if they want to participate. One of the strategies used was to ask the parents what type of activity they would like, to hopefully encourage participation by through the use of choice as motivation to attend and participate.

\subsection{Context}

Hay Branch Elementary has grades PK-5 with about 679 students in the school. Average student to teacher ratio is 15:1 but can vary between grade levels and type of classroom, such as special education. Those numbers can be higher or lower depending on the needs of students. The student population is made up of 80\% minority students with the majority being African American students. The schools is near Fort Hood, which is a military base, this means there can be high student and teacher turnover. Hay Branch Elementary school operates within the Killeen Independent School District in Texas. The Action research took place in a self-contained classroom that served students in grades K-1. The classroom has about 13 students and can increase or decrease in size during the school year. A teacher and two full time education aids worked in the classroom with students. Most students spend a majority of their day in the self-contained classroom getting all academic instruction as well as small group and individualized instructions on their own personal academic and behavioral needs. Students go to elective classes with an aid. A majority of the students have Autism with other academic and behavioral needs, or comorbid intellectual disabilities that made them eligible for self-contained services. This classroom serves other students from around the district to support students who cannot access services from their home school. The sample size used in the research was unintentional. It consisted of the makeup of the students in the room. A larger sample size was not considered due to time constraints and it was not school wide since teachers at all grade levels chose their own methods of communication. Permission was given by the school and by parents by signing and agreeing to participate with the option to stop participation in the research process at any time from August 2016-November 2016. Information about students' was kept general per guidelines from the school district to protect the interests of the students and their families. Basic demographic information is given in consideration of the research study.

\subsection{Area of Focus}

Many reforms have been put into place in an attempt to increase parent in- 
volvement, however, few seem to have staying power. Whether it be communication between teachers and parent's that fail, between the school, teachers, and parents, or a lack of realistic interventions. Early intervention is imperative, especially for students who receive special education services or spend most of their day in a self-contained setting.

The goal of the study was to increase involvement early on in a special education classroom consisting of grades k-1. Specific grade levels were not targeted. My classroom was for $\mathrm{k}-1$ students. I decided to improve my communication within my classroom, thus the strategies used were based on needs of my classroom. Low-tech strategies were used since materials had to be provided by the teacher. High-tech options were abandoned to ensure all parents had access to the same level of communication. Parents were encouraged to visit the classroom. District guidelines asked all parents to follow specific guidelines to in the best interest of student safety and school safety. Guidelines stated that parents: sign in the front office at the school, getting a visitors pass, and letting the teacher know a couple hours before hand. These are district guidelines and were followed by all said schools within the district. Parents or guardians who wanted to volunteer had to follow another set of procedures designed by the school district. These guidelines may inhibit parent/guardian participation and open communication. However, those topics were not studied in this research, but do offer other areas in which to study in the future. Strategies that were used consisted of using a classroom newsletter, Class DOJO ${ }^{\mathrm{Tm}}$, and in-person classroom activities. The newsletter served as a basic level communication tool that covered weekly events and general information. Class DOJO ${ }^{\mathrm{Tm}}$ was aligned with the classroom behavior management strategies that gave daily updates, and the classroom activities consisted of those requested by parents to support parent/student development.

Special education students' are just as susceptible to feeling unsuccessful at school. Students can develop a poor self-worth due to limitations in academic and social competence. When schools adopt successful strategies; parents, schools, and teachers can work together to help every student be successful.

The purpose of this study was to outline strategies that can be used to increase parent involvement in schools and how to apply them in day to day practice in a special education setting.

\section{Information for Action}

This study aimed to improve communications, relationships, and involvement of parents within a special education classroom. With the use of indirect and direct methods of communication alter participation and communication between parents, teachers, and schools. Teachers may assume parents' would prefer more direct forms of communication over indirect, however, that may not be a preferred method. Instead it could be making parents feel disconnected from the school and teachers (Bartle-Haring, Younkin, \& Day, 2012: 193). Just like students, not everyone likes to engage in the same forms of communication, three 
strategies were used to meet the needs of all parents. These strategies were used in a special education classroom that allow for indirect and direct communication and involvement with parents.

\section{Background Information}

In previous school years, ("Hay Branch Elementary School Profile," 2014) "the student population is consistently made up of about $69 \%$ minority students in the school. Over half of the students are eligible for free lunches and about $10 \%$ are eligible for reduce school lunches. The school is almost at an even split between male and female students, with female students normally $1 \%-2 \%$ higher depending on the school year." Mixed reviews of school support, communication, and involvement can be found online. It is important to note that there are less than 10 reviews. Mixed reviews of special education services/parent involvement have only been established by word of mouth. Specific interviews or surveys are not documented for special education. The self-contained classroom is mostly male students with and a very small portion being female students. It is very common for the classroom to have 1 - 4 female students or none during the course of a school year. An exact approximation cannot be made due to the frequency of students that move, since a majority of students come from military families. Most students are diagnosed with having Autism, some with comorbid intellectual disabilities, some are receiving services for academic needs, or for both academic and behavioral needs. All academic and behavior needs are taught in the classroom in large groups, small groups, and individually. Instruction in based on the academic requirements of the state and district, then individualized to meet all student's needs. Parent involvement has been low, especially within special education classrooms. Many parents work during the day, long hours, or have varied schedules. Making contact more difficult was well as attempts to encourage involvement. It is important to consider the needs of the families, while also recognizing that low income and military families have diverse needs. Improvements to increase communication and involvement will need to reflect those of the families. Direct communication or physical visits to the school can be difficult. Having some choices available and some flexibility will be important to try to engage parents and increase both communication and involvement.

\section{Literature Review}

Define abbreviations and acronyms the first time they are used in the text, even after they have been defined in the abstract. Abbreviations such as IEEE, SI, MKS, CGS, sc, dc, and rms do not have to be defined. Do not use abbreviations in the title or heads unless they are unavoidable.

\subsection{Communication}

Getting parents involved in their child's education may be a very important aspect to overall student achievement. Understanding what parent's would like 
communicated to them is an important and may help increase communication between teachers, schools, and parents. According to Colley et al. (2014) communication strategies that connect parents to teachers, schools, and allow them to contribute to decision making is an important factor in creating an environment that welcomes interaction. However, this is twofold in the aspect that parents have more responsibilities besides the norms of making sure their child makes it to school every day. This may be somewhat controversial depending on the state, community surrounding the school, and socio-economic status, and a parent's ability to help or be willing contribute. This study took place in Gambia, where community involvement is a norm and an expectation to help every child succeed in school. Other research seems to agree in the efforts that engaging parents in communication can help improve student success in a special education setting. Those efforts involve both indirect and direct communication strategies. One study utilized weekly messages written by teachers to look at the effects of that type of communication. The study took place during the summer and was conducted in an urban school setting. Their study looked at the effect of parent-to teacher communication and if the type of message increased or decreased the likelihood of communication, i.e., positive or needs-improvement based notes. In the study parents were assigned to groups of positive messages, needs-improvement, or the control group. Messages were collected each week from the teachers and worked into a standardized script that the researchers would communicate to the parents by phone, e-mail, or text depending on how the parent wanted to be contacted. Translators were hired to translate non English speaking parents. Results of the study indicated that communication was important and helped reduce the dropout rate of high school students by half in the summer program. It also pointed out that the content of the messages were very important. Messages that contained information about improvements the student had made a difference in the dropout rates. The students in the group that messages were based on needs improvement saw an increase in the number of students that received credit for their summer course and that individualized messages could be a low cost way of improving communication from teachers-parents and improving student academic achievement.

\subsection{Parent Involvement}

Research states that parent involvement is embedded in Federal policies and is mentioned over a thousand times in IDEA of 2004. Meaning that it is an important part of education and in special education as well. Even with mixed results and little research, involvement continues to come up. It was suggested that the use of newsletters, updating parents on their child's development, and allowing them to have a part in the decision making process for their child's education. In special education a way to include those would be to send home a classroom newsletter each week, sending home progress reports, and involving parents in giving feedback on the development of goals for their child. It is also noted that the fact that parent involvement is termed as many things or imaged in different 
ways can make it difficult to truly understand what "good" parent involvement looks like can be confusing. It may add to the lack of information surrounding parent involvement and whether or not there are more positive or negative effects surrounding the information.

\subsection{Family Engagement}

Distance and family demographics such as parenting behavior and routines may have an impact on how involved parents are with their respective schools and how they like to be involved as well (Bartle-Haring \& Youkin, 2012: 192). For instance some families and parents are highly involved in their child's education and carry those behaviors into their routines and doing things actively and directly with their child. Bartle-Haring et al. (2012) talked about the idea of "spillover" which is the idea that the routines at home and at school could be tied to student success at school. Students could have more difficulty in school where relationships at home are not as closely cultivated because parents are not as actively involved and take a more indirect approach to raising their child and with their education. Whereas on the other hand some parents are so involved it also hinders their child in their ability to develop autonomy within the family unit and in school as well (Bartle-Haring et al., 2012: 193-194). Finding a balance between indirect and direct methods of parent involvement are important to try to meet the relationships parents carry out at home and might show up with their involvement in their child's education as well. Not all methods will work well with parents that have a more indirect relationship with their child and the same could be said for parents that are actively involved may not respond well to indirect methods used by a teacher or school. Finding a balance seems to be important to keep in mind when trying to work with different families within a school setting. The terms direct and indirect used in this research study are simply used to reiterate the fact that families have different ways of interacting with one another and that preference should be considered when schools and teachers communicate with families. While some parents/guardians may prefer phone calls, other parents/guardians may see this as an invasion of personal boundaries and create an adverse reaction. Thus it is imperative that those perspectives be considered and questions about how families would like to be communicated with be respected and followed through with. Both indirect and direct methods of communication are included in this study to support the needs of all families within the study.

\subsection{Socioeconomic Status}

Parent involvement was defined by Henrich \& Gadaire (2008) as a "variety of parenting practices that is connected to their child's education." This included involvement, communication, school-parent relationship, the school- community relationship, and parent learning (Henrich et al., 2008: 56). Several factors that Bartle-Haring et al. (2012) referenced were: father's age, father's education, income of the family, mother's age, mother's education, the child's sex, and eth- 
nicity of the family. This study did not take into account single parent families or families that involved remarried parents and the dynamics that may also affect how families interact with teachers and their respective schools. The parent's ability to get to the school, work schedules, and available resources can be contributing factors to the amount of time a parent has to be involved and how they communicate with teachers and schools. Understanding the diverse needs of families is important to trying to improve communication and involvement in schools. A great example of this would be Head Start programs that used to rely heavily on parent involvement to help maintain the schools, encourages parent volunteering in classrooms, and at activities at Head Start. This was a great a way to get parents involved, help families, and communicate with families actively. However, when changes were made to Head Start programs involvement decreased due to the welfare reform, where parents were then required to seek out and find a source of employment or risk losing their welfare benefits. This increased the amount of stress on parents because they now had the stress of getting to their jobs on time, needing additional care depending on the Head Start program, and were spending more on expenses to get to their jobs, child care, and were still considered in poverty. The addition of having a full time job or several jobs did not help decrease their need for welfare or get them out of poverty. As a result there was a decrease in volunteering and parent involvement at Head Starts across the United States. This meant that the responsibilities of keeping up the maintenance of the buildings often feel on the teachers who also made considerably less than teachers that did not work for a Head Start program. Not only were teachers being overworked, but parents were seen less and less as the requirements to maintain benefits were becoming increasingly more complex (Henrich et al., 2008: 59-64). Research was include on socioeconomic status due to the fact the placement of the school was in a lower income area, the need for free and reduced lunch at the school, and data that can be found online. An in-depth study of income levels was not included due to the fact that low-technology options were included in the research study to compliment the needs of all families. It was not necessary for all families to have access to internet or specific programs if that was not an option for them. Low- technology options was purposeful in this study and was used to meet the needs of all families.

Most research seemed to be a reiteration of other studies. No real new ideas were evident per reading through research. However, what really seemed to be important was paying attention and understanding the community that a student comes from. There are many factors outside of school that seem to influence how communication will play a role in a child's education and how that information is relayed to parents. These relationships seem to be more difficult to cultivate when there are other factors that may play a part in how often or how much a parent would like to communicate or what their expectations might be. Taking that into consideration seems to be an important part of developing communication that is meaningful and possibly aides in the success of students and relationships cultivated between teachers, schools, and parents. What stuck 
out the most to me was really understanding how parents communicated whether it was more direct or indirect since my delivery of information could contain a combination of both, it would seem that it would be important to have a couple ways to relay the same information to best meet the needs of the parents I communicate with during a full school year or longer depending on the program my students are in. I learned that I needed to pay more attention to minor or smaller details in hopes to try to advance my communication with parents and possibly be more effective and also try to improve student success in a special education classroom.

\section{Research Questions}

- How will the use of direct and indirect forms of communication effect parent participation in a K-2 special education classroom?

- Will using choice increase parent participation in classroom activities in a $\mathrm{K}$ - 2 special education classroom?

- Will parents feel satisfied with their involvement in their child's education compared to feeling unsatisfied, with the use of direct and indirect strategies for communication and participation?

\subsection{Action Plan}

Since communication with parents seems to be a corner stone to increasing student success and parent involvement. I used 3 strategies to attempt to increase communication and involvement in a special education classroom. Students range in grades from $\mathrm{k}-1$, I hoped to implement strong communication and involvement strategies. To help lead to a positive outlook on the school, myself as a teacher, and help parents become involved in ways that best meet their needs.

Two Indirect methods were utilized to attempt to account for the various needs and preferences of parents. In an effort to meet all needs of the parents, too often it seems communication breaks down soon after the school year starts, however, my goal was to create methods of communication that I utilized daily/weekly to improve communication and involvement with parents in a special education setting. A time line was created to ensure that all aspects of the research were carried out to the best of my ability to keep track of data to be collected and all aspects of the action research.

\subsection{Sample Demographics}

The special education classroom is made up of 4 girls and 6 boys in a suburban area, a part of a very large school district. The grade range was $\mathrm{k}-1$ and all students have varying needs and have wide ranges in academic abilities. There was not a specific selection process or criteria to be included in the research study. Parents either gave permission or chose not to participate in the study. All parents chose to participate in the study as long as specific information about their child was not included in the study as well as their likeness or image. This also follows guidelines within the Killeen Independent School district. The sample 
size was made up of students with autism, Down syndrome, and a combination of co-morbid intellectual impairments along with medical needs. Again, specifics and names are left out in order to follow district guidelines and parent wishes. Many students worked on counting, recognizing numbers, writing their name, and worked on social skills as a part of their program. A majority of the male students have autism with co-morbid health related issues or other disabilities occurring with the autism, have used physical aggression as a means of communication, one student has Down syndrome, and one is legally defined as mute. Female students consisted of those with autism, downs syndrome, and intellectual learning disability with co-morbid medical needs, and speech and language needs. Many students struggled with communication and are struggling to learn various ways to communicate. Ways students are learned were through augmentative devices, sign language, speech therapy, and a combination of some or of all of those options. Communication seemed to be very important to parent's based on comments from Meet the Teacher night, when most questions centered around how I would communicate their child's day to them, specifics on how it went, what they did, and how they liked to be contacted. Since their children have difficulty communicating their day, it seemed as though communication for this classroom, in particular was important. Students in the K-1 special education classroom are majority African American students, Hispanic students, and the lowest ethnicity in the room being Caucasian students.

Samples were obtained by using mixed methods, such as questionnaires, and frequency count on returned and signed newsletters. Parents were given a contact form that will specify 3 methods: e-mail, phone, written notes, and ask them to order them by their preference. This was completed at Meet the Teacher Night and via student binders if the parent is unable to come to Meet the Teacher Night. Three attempts were made, dated, and documented in the event parent's decline or avoid completing their preferences for communication. Questionnaires we adapted from looking at communication flyers sent home to parents, forms filled out by parents when they register their child, and based on first interactions with parents from meet the teacher night. I based it on interactions with parents from day to day when they picked up their child or general inquires that were brought up during the first weeks of school. I took into account the needs of the parents and conversations to justify the questions in the questionnaires. The use of low-tech options was intentional to decrease demands on myself as a teacher and ensuring I maintain high fidelity on my end and that is was accessible for parents. Analysis of at home activities was left out of this study due to the fact that a majority of the families went to programs after school such as various therapies and programs that supported the individual needs of each child. Taking this into consideration, at home activities was left out to not add more to each student's schedule after school. Homework was not typically assigned until after the second half of the school year when school readiness skills have had time to be taught and supported for all students. Homework/at home activities discussions occurred during the second parent teacher conferences that 
happened in January. Thus, was not relevant to the study at this time. However, future research that included this component would meaningful to understanding all aspects that affect communication between schools, teachers, and parents.

A weekly classroom newsletter was created and sent home on Monday of each week that tells the parents about important dates, events in the classroom, what we are learning, and any other important school information will be provided or commonly asked questions that are harder to locate answer for, such as how we celebrate birthdays, changes of clothes, new school snack policies. Parents were asked to sign and date the newsletter as a means of checking to see if they at least glanced at it and when they did. Parents had until Friday of that week to sign and date it. A notes section was added for parents to write any questions or information they would like me to add in the newsletters.

Classroom Dojo was used to communicate daily behavior reports and keep a record of the behavior. Specific behaviors have been coded on the class reporting system to give parents more specific information about how their child's day went. Instead of giving a student a point for a "good job," students will be awarded a point for walking in the hallway, completing work, helping a friend, communicating needs throughout the day. There was a bank of 10 positive phrases. I created a bank that contained behaviors to work on. Examples of these behaviors were: running, hands on others, shouting, throwing objects, incomplete work. There was a bank of 10 phrases as well. This was utilized as a means to communicate indirectly daily and weekly behavior reports on every student. Weekly reports were sent through e-mail if the parent requested and by student binders in their backpacks. The reports required a signature and date to see if the parent looked at it and when. I utilized e-mail settings that allowed me to know that the e-mail was received and opened. I will keep a data sheet that records the date that the email was sent and received by the parent. It is important to mention that this method was discontinued early on in the study due to lack of participation from parents and lack of meaning for students. A back up behavior support was utilized that students demonstrated they could understand. They demonstrated understanding by being able to use verbal means or visual means to communicate their understanding of the behavior chart and how they could earn positive reinforcements. Students also helped pick the reinforcements used.

\subsection{Survey Information}

Survey for in-person classroom activities were utilized at the end of every direct meeting with parents. Parents have expressed wanting to learn how to implement transitions from at home activity to activity and how to implement communication supports at home to understand what their child wants and needs. A survey would be sent out with 2 dates and time choices along with 3 possible activities that they can choose from based on verbal communication from Meet the Teacher Night and will have a space to provide other areas of interest. Activities would be chosen based on the top two most reported interests from parents. Letters would be sent home with dates and times so that they can plan to attend. 
Reminders will also be sent home the Friday prior to the activity.

Survey for overall satisfaction of communication and involvement methods was used and contained 7 questions. A Likert scale from $0-5$ will be used to better help parent's gage if they feel more involved in their child's education and if they have positive feelings about their involvement, the school and the teacher.

Weekly notes from parents were recorded, questions asked, or any other forms of communication in direct result of the indirect and direct forms of communication used. Newsletters and Classroom DOJO ${ }^{\text {tux }}$ had space for parents to ask questions or record comments. The questions and comments will be recorded on a separate data sheet and coded based on typical or frequent comments/questions.

Questionnaire: was created to get suggestions of activities that parents would like to see in the classroom and gather information on what times would work best for parents during the week. The questionnaire asked questions about what days of the week would work best, times during the week, suggestions for activities, and suggested duration between 20 - 35 minutes. Additional space for comments was provided to allow parents express any other opinions or suggestions. Each contained 7 questions, a comments section, and signature and date lines. This was help record who has responded and who has not. Some parents had their questionnaire e-mailed to them per their request and their e-mail and response back will count as their participation, signature/date when returned via e-mail. The information collected from the questionnaire would be used to help create the activities and times and dates that they are offered.

\section{Intervention Description}

Weekly Newsletter: Were sent home every Monday to inform parents of what was taking place in the classroom. Important information such as academic topics covered, social emotional skills covered, special school events, important school dates, classroom wish list (used to collect school supplies when needed, but is completely voluntary), and any other important information that parents needed to know for the week. A simple newsletter template downloaded from Teachers Pay Teachers ${ }^{\mathrm{Tm}}$ was used and I added signature/date, and comments section. Newsletters went home in students take home binders and was used as a way to send important papers back and forth to parents. Parents had until the Friday of the current week to return the newsletter signed and dated.

Classroom DOJO ${ }^{\mathrm{m}}$ : was an indirect method used to collect classroom management information for parents. I went to the Classroom DOJO website and signed up by using my school email and created a password to create my account. I added all the students from my class roster and just used first names and last name initials. After creating my class I added in the 10 positive behavior phrases and kept them short and specific so parents would easily be able to understand behaviors that are being supported in the classroom. An example would be walking feet, completed work, etc. I also created 10 behaviors that students are working on, students earn zero points when these behaviors are dis- 
played. Behaviors like hitting, running, incomplete work, yelling are noted in this section. This allows parents to clearly understand why a student was not awarded a point. Instead of negative points, I kept it zero to remain neutral and purposely avoiding a punitive point system. Since some forms of behavior are directly related to lack of communication and lack of social and emotional skill development. Student's received 1 point for every positive behavior choice displayed. Students needed to earn 5 points before they earn a 3 minute free choice break, where they choose between puzzles, drawing, or reading a big book of their choice. Choices and criterion of points were increased as the school year progressed. A Point system and coded behaviors were based on individual education plans and common needs of all students within the classroom. Parents were given the Classroom DOJO ${ }^{\mathrm{m}}$ generated "how to" join page that gave step by step directions how to join our classroom DOJO ${ }^{\mathrm{mm}}$ account. Parents could choose to be e-mailed reports or have them printed out as well. I sent direct comments to parents weekly.

In person classroom activities: These activities would take place twice during the action research project and will be a result of the parent suggestions of activities they would like to attend and for me to organize within our classroom. They would last between 20 - 30 minutes and involve them interacting with their children. Explicit Direct Instruction will be used as the choice of lesson plan delivery so parents also are able to experience how their child is being taught. The same transition and auditory signals were used to help guide parents through the activity. During the last $5-7$ minutes of the activity parents will be given a survey to fill out using a 0 - 5 Likert scale and a comments section for any addition comments. They were not asked to sign it so they did not feel pressured to supply any specific opinion. The parents would put their survey in a manila folder placed on a table in the classroom before they leave. Parents would have the opportunity to attend one or both of the two classroom activities that will be offered and the same procedures will be followed for both activities.

\subsection{Data Collection}

Data collection was designed to meet the busy schedule of any teacher that experiences the day to day rigor of being a special education teacher. With the amount of responsibilities within and outside of the classroom, data collection needed to be systematic, simple, and low-technology in order to keep up with the demands of ensuring fidelity. The weekly newsletter and weekly behavior chart were easily collected since it was worked into the weekly routine of the classroom and there was a designated each time every day where the "take home folders" were written in and sent home with the students before they left for the day. This kept a very consistent method of collecting data. As for the questionnaires and surveys those were easily maintained because a schedule was created of when they would be sent home and collected. The information from them was used to inform decisions during the research study. Since this information was imperative to the research study it was collected, analyzed, and utilized imme- 
diately to help improve the action research study and overall reaction to the communication methods used. Knowing ahead of time the technology restrictions and possible needs of the families, informed the decisions on how data would be collected. The design of the study was to keep the methods reliable, simple, and easily replicated to encourage other teachers in special education to improve their communication methods with their parents/guardians. Mixed data collection methods were utilized to gain information about the thoughts, perceptions, frequency of how often parents looks at indirect methods of communication, and overall agreement or disagreement with the direct and indirect methods used to increase communication and involvement in a special education classroom. Since many parents are working and have varied work schedules surveys will be utilized to gain information and a questionnaire was utilized to obtain information before planning and organizing the in-classroom activities. The frequency at which parents look at information sent home was important to know and helped me gage how often to send information home in the future. In my study I wanted to understand the perceptions, opinions, and suggestions from the parents to help guide efforts to increase communication and parent involvement in a special education classroom.

Prior experience has left me feeling that this was an important area that I needed to concentrate more efforts in and I feel that involvement was improved between parents, the school, and myself as the teacher. Since communication can be strained due to the nature of special education. My goal is was that the information gathered would help to improve my practice, communication, and involvement within my classroom.

\subsection{Data Sources}

- Communication Survey-A seven question survey that utilized a 0 - 5 point Likert scale will be used to gain perceptions and overall opinion of how relevant and helpful the communication methods in the classroom were. Parents would select not at all, somewhat, no feelings either way, agree, or strongly agree to answer questions. An additional comments section would be used to allow parents to express any other thoughts or opinions.

- Involvement Survey-A seven question survey that utilized a 0 - 5 point Likert scale will be used to gain perceptions and overall opinion of how relevant and helpful the communication methods in the classroom were. Parents would select not at all, somewhat, no feelings either way, agree, or strongly agree to answer questions. An Additional comments section would be used to allow parents to express any other thoughts or opinions.

- Activity Questionnaire-Would be used to gauge what times, days, and what type of activities parents are most interested in. Parents would have a choice between 3 times, three different days of the week, and yes/no questions that pertain to types of activities that could be offered to parents. A comments 
section would be provided so that parents are able to add any addition comments or ideas of activities that they would like to see in the classroom.

- Classroom Newsletter-Would have a signature/date section at the bottom of the newsletter for parents to sign and date that verifies that they have read or at least seen the newsletter that was sent home via the students backpack. Newsletters would also be e-mailed per parent request and e-mail settings will help verify whether or not the e-mail was opened and parents will be able to email back questions and comments to the teacher of which will be saved, answered, and documented weekly. Parents were be asked to sign/date and send in comments by Friday of the same week to help prepare the newsletter for the following week.

\subsection{Timeline}

A timeline was created to maintain fidelity within the study. Specific dates were set to send home the questionnaires, and surveys in order to gather information from parents to make any adjustments to the study as it progressed. The newsletters and weekly behavior charts were sent home every Monday of the following week until the following Monday of the next week. Information from both papers was collected and data was synthesized for each week of the action research until the end of the study. Information regarding the timeline can be found detailed in Table 1 . The date items were sent home, the frequency, type of data, and information are provided in the table.

\section{Interpretation}

Many adaptations were made during the course of this action research project.

Table 1. Timeline for Action Research: to ensure fidelity with data collection, scheduling, and ongoing communication methods are documented and carried out.

\begin{tabular}{|c|c|c|c|}
\hline \multirow{2}{*}{ Date: } & \multicolumn{3}{|r|}{ Timeline for Action Research Project } \\
\hline & Frequency & Data Type & Information \\
\hline August 18, 2016 & $1^{\text {st }}$ attempt & Survey & Communication preference \\
\hline August 22, 2016 & $2^{\text {nd }}$ attempt & Survey & Communication preference \\
\hline August 22, 2016 & Weekly & Frequency & Student behavior \\
\hline August 22, 2016 & $1^{\text {st }}$ attempt & Questionnaire & In-person activity-planning ${ }^{\star}$ Removed from study \\
\hline August 29, 2016 & $2^{\text {nd }}$ attempt & & In-person activity-planning ${ }^{\star}$ Removed from study \\
\hline Sept.-Nov18, 2016 & Weekly & Data collection & Review Data \\
\hline Oct. $3-31,2016$ & Weekly & Data collection & Review Data \\
\hline Nov. 1-11, 2016 & weekly & Data collection & Review Data \\
\hline November $07-15,2016$ & Final attempts & Survey & In-person activity Overall satisfaction of communication methods \\
\hline
\end{tabular}


Some of them were surprising on what worked, what didn't work, and items that were just not possible during the time frame of the research. In the first two weeks of the study the Classroom Dojo ${ }^{\mathrm{mm}}$ program was dropped. It had 20\% parent participation and provided no information to students that they could understand. Parent feedback proved to be one of the most promising efforts made in improving parent communication. This was directly applied to the weekly behavior sheet that was sent home daily. I recorded the behavior daily and wrote a paragraph weekly to specifically report how the student has improved and one thing we are working on. I added a smiley face system to the feedback sheet after parent feedback requested it. I added it the color behavior chart in the classroom to help provide feedback to student's on their behavior as well. This provided more of a concrete image for students and they were able to understand the feedback I was given to them. I decided remove the direct activities from the classroom due to the severity of behaviors within the classroom and ensuring the confidentially and safety of students in the classroom. This would be something to revisit further into the school year and possibly try later on when behaviors within the classroom and environment are more stable. Some of the parent conferences helped to confirm that parents did read the comments made on the weekly behavior sheet. Parents reported it was helpful at home when working on academic and social emotional skills. These responses were not recorded from the parent- teacher conferences, but provided a positive experience between the parent and myself having the background communication initiated prior to the meetings. Overall preferred methods of communication are documented on Table 2. Many parents seemed to prefer indirect methods of communication which was an interesting point in the study. Table 3 listed comments that were given back on the overall satisfaction questionnaire. While Table 4 documented the overall satisfaction using a Likert rating scale from $1-5,5$ being very satisfied and 1 being not satisfied. Most of the comments were positive and one seemed to evaluate overall satisfaction to be met if the same methods of communication were continued throughout the entire school year. This may lead to suggestions that consistency is very important to parents in how they view overall satisfaction.

Table 4 Comments from the questionnaire: The comment of " $1^{\text {st }}$ year at school." corresponded to the "no opinion" with a score of 2 using the 5 point Likert scale. This is important to note because it was the only response of this

Table 2. Preferred Method of Communication: was utilized to understand the communication needs and preferences of parents. Parents filled out a survey and returned it to the teacher during Parent/Teacher night or via back pack during the beginning of school in August.

\begin{tabular}{cccc}
\hline & Written Message & Call & E-mail \\
\hline First Choice & $9 / 10$ parents & $\mathrm{X}$ & $\mathrm{X}$ \\
Second Choice & $\mathrm{X}$ & $7 / 10$ & $\mathrm{X}$ \\
Third Choice & $\mathrm{X}$ & $\mathrm{X}$ & $3 / 10$ \\
\hline
\end{tabular}


Table 3. Comments from Satisfaction Communication Survey: this is a table of comments from the questionnaire. The comment of " $1^{\text {st }}$ year at school." Corresponded to the "no opinion" with a score of 2 using the 5 point Likert scale. This is important to note because it was the only response of this kind reported from the questionnaires.

\section{Comments From Satisfaction Communication Survey}

1) "Kim and the other teachers have been nothing but caring and kind."

2) "Been satisfied with the start of everything this year, keep up the great job!"

3) "1 1 st year at school."

Table 4. The communication Feedback Questionnaire: Parent that listed 2 for question four for "no opinion" and wrote comment, "1 1 st year at school." A rating scale was used from $1-5.1=$ not satisfied, $2=$ no opinion, $3=$ somewhat satisfied, $4=$ satisfied, $5=$ very satisfied.

\begin{tabular}{cccccccccccc}
\hline & P1 & P2 & P3 & P3 & P4 & P5 & P6 & P7 & P8 & P9 & P10 \\
\hline Q1. & 5 & 4 & 5 & 5 & & & & & & & \\
Q2. & 5 & 4 & 5 & 5 & & & & & & & \\
Q3. & 5 & 4 & 5 & 5 & & & & & & & \\
Q4. & 5 & 4 & 5 & 5 & & & & & & & \\
Q5. & 4 & 2 & 5 & 5 & & & & & & & \\
\hline
\end{tabular}

kind reported from the questionnaires. Parents were not required to put their name on the form and were able to send them back in an envelope addressed to the school if they wished to return them in their take home folder that went in their child's back pack to and from school.

\subsection{Interpretation of Research Questions}

Research Question One: How will the use of direct and indirect forms of communication effect parent participation in a $\mathrm{K}-2$ special education classroom?

Figure 1 and Figure 2 look at the percentage of indirect parent participating on a weekly basis by initiating the weekly behavior chart which communicated how their child was doing behaviorally with a paragraph provided each week of 3 positive notes and 1 item to work on. While the newsletter let parents know what academic skills students were learning in the classroom, important school events, and other important information with dates, times, and location provided for ease of use. Parents had to initial or sign that they had at least seen the newsletter and those percentages were calculated on a weekly basis to see if there were trends within specific months during the study.

The use of indirect forms of communication seemed to be helpful in creating positive relationships between myself and the parent/guardian. Parents seemed to be more open to positive and constructive feedback about their child. They seemed more willing to work together on those issues that presented themselves throughout the action research project. Data from indirect forms of communication can be found in Figure 1 which shows the data collected on the use of 
WEELY BEHAVIOR CHART

-Month 1 Month 2 Month 3 Month 4

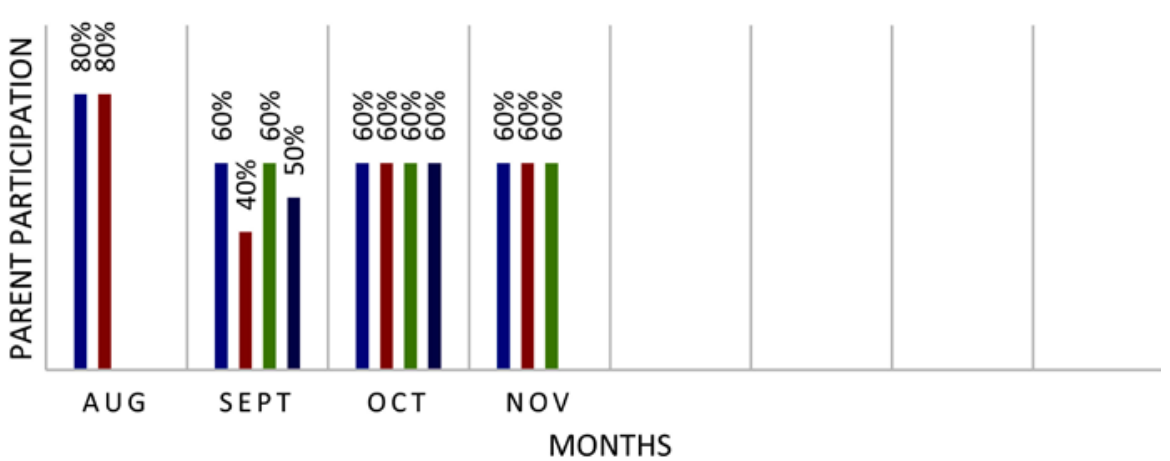

Figure 1. Weekly Behavior Chart: The data below tracked the weekly behavior charts that were returned signed the following week. The behavior charts were sent home the first Monday of every week and signatures were recorded the Monday of the following week.

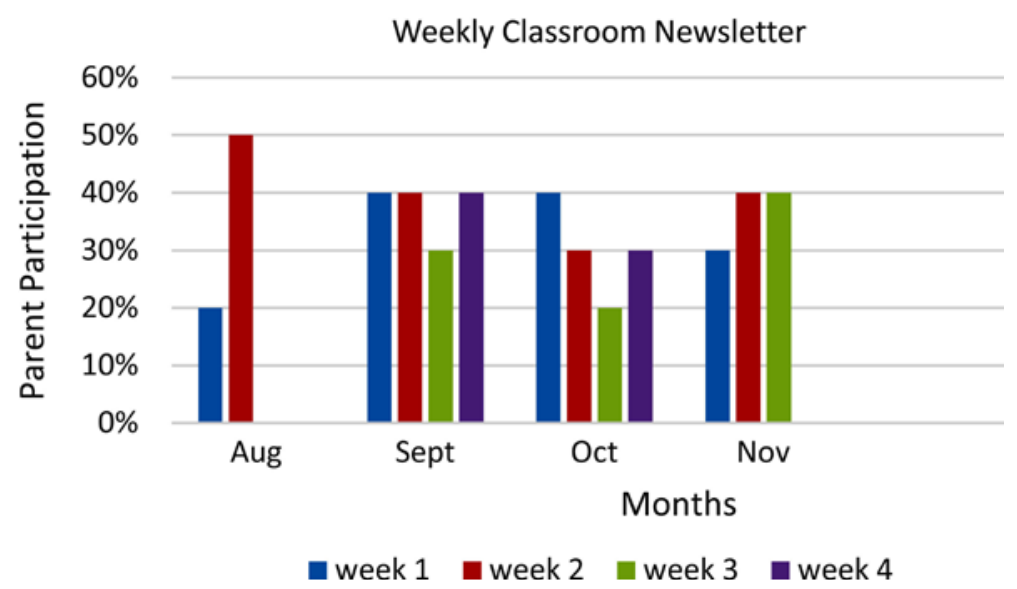

Figure 2. Weekly Classroom Newsletter: Shows the percentage of indirect participation via signatures by parents weekly. Newsletters were sent home every Monday and signatures recorded every Friday for data collection.

classroom newsletters and how effective it is as indirect communication. The improvement in communication on behavioral factors could have been due to positive associations to the smiley face system due to a possible decrease in school related stress. Research has shown that there are direct relationships between stress and school engagement that families experience, (Bartle-haring \& Youkin, 2012: 197). There were several instances when meetings needed to be held to discuss student's behavioral or academic support needs. All meetings were positive in the fact that both the parent and I were able to work on the issue at hand and implement parts of the support in school and at home. Some parents used the feedback to implement extra academic practice of skills at home based on the feedback on the weekly behavior sheet.

Research Question two: Will using choice increase parent participation in classroom activities in a K-2 special education classroom?

This question was not answered during the current action research within this study. Direct activities were not implemented due to the severity and frequency 
of behaviors within the classroom. It was important that the safety of all students and environment be considered before adding extra variables into the environment that could trigger more severe behaviors. The decision was made to not implement this portion of the research due to the safety of all students. A more developed understanding of family distance regulation would be necessary to have a more informed idea of how to create stronger relationships geared toward participation and engagement (Bartle-Haring et al., 2012: 201). Since family distance regulation can play a role in how schools should encourage participation from families which is turn could improve student success. Indirect participation data was collected and showed that there was a fair amount of consistency from month to month. With most of the participation taking place during the first month of school, Figure 2 depicts the percentage of parent participation via signature that they looked at the classroom newsletter. The classroom newsletter contains important dates, school policy reminders, our weekly fun Friday science experiment, and academic information about what student are learning on a weekly basis.

The percentage of participation was not high, at the highest it was $50 \%$, and that only occurred one week in the beginning of school in August. It maintained somewhat at $40 \%$ in the month of September and in October the percentage of participation is declining and with the third week having only $20 \%$ participation. This could be due to the length of the newsletter and readability of it. It could be due to deployments and soldiers coming home from deployments and how that changes daily routines. The second newsletter in August was short and had bulleted information and only two areas where there were short paragraphs that contained 4 sentences. As the school year progressed there was more information and the newsletters became denser in information which be one of the reasons why I am seeing a decline in participation. I have also had to send more papers and forms home for school that I did not create, but needed to be sent home. It could be a possible variable with higher amount of papers being home, it might have an effect on parents reading the newsletter. The first week of every month seems to show the highest rates of participation across the three months thus far. Then during the month the participation seems to decrease as the weeks go on in every month. October and November showed similar results with participation staying between $30 \%-40 \%$. The last week of November was not completed due to a week off for Thanksgiving break.

Research Question three: Will parents feel satisfied with their involvement in their child's education compared to feeling unsatisfied, with the use of direct and indirect strategies for communication and participation?

Data from the questionaries' is found in Figure 3. The information from the data collected seems to show that a majority of the parents were satisfied with communication efforts and were focused on seeing if the efforts maintained throughout the school year. At least 50\% - 75\% reported being very satisfied with the communication efforts being used. Karakus et al., (2012) have found that, "Parental involvement in their child's schooling has been consistently shown to 




घ $\square 4=3 \square 2 \square 1$

Figure 3. Overall Communication Satisfaction: Overall percentage of parent satisfaction with indirect communication used during the research study.

children's school success (pg. 1)." Most communication efforts were indirect besides the parent teacher conferences and meetings called during the school year to discuss various supports needed for the students within the classroom. One parent did report no opinion on one of the questions in the questionnaire but gave an overall rating of satisfied.

Figure 3 shows results from the Overall Satisfaction Communication Questionnaire. The bar graph shows percentages overall of how parents reported their satisfaction with communication efforts. Most $50 \%$ or higher reported being "very satisfied" with communication efforts. $5^{*}$ (very satisfied), $4^{*}$ (satisfied), $3^{*}$ (somewhat satisfied), $2^{\star}$ (no opinion), ${ }^{\star} 1$ (somewhat satisfied), ${ }^{\star} 0$ (not at all). There were no reports of parent's satisfaction being below satisfied, besides 1 report of "no opinion."

Data from the communication feedback questionnaire will be recorded in the table above with an explanation of the table. Another graph will be below this table to show the average values from each question using a Likert scale to put a numeral value to how the parent's about the communication efforts being made to help keep them updated on weekly information in the classroom that includes academic updates, behavioral updates, curriculum updates, and any other appropriate information that they may need or want to know. Questionnaires were collected by the first Friday in November to allow for parents to have time to respond.

Direct communication was not documented because it was not directly apart of the research study. These items included IEP meetings, parent/teacher conferences, and behavior support meetings, daily communication due to the child being parent pick up, and opportunities to talk the parent directly from those encounters. Developed trust between parents and teachers has a positive association towards students and school. When parents are more involved teachers and parents are able to develop trust between one another, (Karakus et al., 2012: 7). This directly impact students and creates more trust between the teacher with students as well. Those responses could be recorded and coded for future re- 
search efforts to code common questions and responses and teacher might encounter in a special education classroom.

\subsection{Limitations}

I was unable to implement the direct activity portion of the action research due to the severity of behaviors within the classroom. In order to maintain confidentiality and a safe classroom environment that part of the action research project was not implemented. This is due to the time frame in which the action research project was implemented and maintaining a stable environment for students. This part of the action research project may be possible further into the school year when more behaviors are under control of behavior intervention plans that have had time to resolve most behaviors within the classroom.

Many positive comments were communicated by parents during the action research project, however, they were not explicitly recorded unless they were written on the overall satisfaction communication questionnaire. Future research should include comments made by parents to see if methods of communication used improve parent's overall satisfaction as the school year progresses by being able to provide a way to code responses and how many responses are obtained over a specific period of time.

Some parent feedback was utilized in the study and is noted in how it was used to improve specific aspects of the research. Most of the parent feedback was about making the weekly behavior chart more understandable by adding a smiley face system. This was added upon parent feedback and was added within the classroom. It helped both the students and parents better understand how the student's day went. The visual was very helpful to students and they were able to relate specific behaviors to the smiley faces.

I was not able to compare direct with indirect forms of communication because I did not collect data on direct forms of communication, since it was eliminated from my survey due to the severity of behaviors within the classroom. Future research could record communication in direct circumstances from various in person meetings such as parent/teacher conferences and weekly communications where the parent comes to the school for various reasons that gives the opportunity to communicate directly. These opportunities were not recorded in this study and could have been a way to compare differences and similarities within the study when looking at indirect forms of communication. This might show support for a combination of both efforts, a strength in one effort over another, or other striking differences that could inform improved communication practices in the future.

\subsection{Next Steps}

The next steps to further what I learned from my action research would be to continue researching each question individually. While I found that some parts of my action research project were successful, I also found that other parts that need further research and exploration. Parts of my research were omitted and 
due to circumstances within the classroom. These were areas I had not put prior thought into while preparing to conduct the research.

In the future I would have benefited from a more in depth study of the community that the school is in, socioeconomics, and interviews with teachers that had the students prior. Since I was unprepared for some of the challenges within the study causing items to be removed. However, without the action research process weaknesses in my approach would not have been as clear.

Question one: How will the use of direct and indirect forms of communication effect parent participation in a $\mathrm{K}-2$ special education classroom?

Future research would look at how to incorporate direct forms of communication and participating within a special education setting. Since I encountered circumstances that prevented me from implementing the direct part of my action research project. I would like to see how I could have incorporated the direct aspect. If I was able to incorporate parents into some part of our day directly it might have had a better participation with indirect methods of communication as well. There might have been more buy into parents involving themselves in the communication and feeling that they are gaining more from their participation. The development of "parent-teacher relationships" is important to building and maintaining "positive consequences that are likely to be repeated".

Question two: Will using choice increase parent participation in classroom activities in a K-2 special education classroom?

I was unable to implement the choice portion of my action research. The choice portion was going to be used to allow parents to choose what types of activities they would like to participate in within the classroom. Successful "partnerships between parents and teachers could help cultivate active participation and willingness by all parties,". From their feedback activities would have been planned for them to attend to incorporate parents into the school routine and to get a feel for how their child experiences learning in a special education classroom. Future research could look into incorporating parents into the school routine more, provide choices for activities within the room for parents to come to or help create, or give some ideas or feedback on how they would like to be incorporated into their child's education.

Question three: Will parents feel satisfied with their involvement in their child's education compared to feeling unsatisfied, with the use of direct and indirect strategies for communication and participation?

I incorporated several indirect strategies weekly into the special education setting. I sent home a weekly classroom newsletter and daily behavior chart that had a paragraph explaining their child's strengths for the week and one area we are working on. The parents were asked to sign the newsletter at some point during the week before the following Monday and initial each day of the behavior chart so I could verify that they at least saw the documents. Parents were encouraged to leave comments or questions for me to answer. Some parents did provide comments or questions when they needed to tell me important information, asking for a specific resource, or just relaying that they were glad that their 
child was making progress. (Karakus et al., 2012: 9) suggest that, "it is helpful for teachers to build relationships with parents and students to help avoid conflict",. I did not implement any direct form of communication within the scope of the action research. On a normal day to day basis I did see some of the parents and would speak with them if time permitted. However, since this was not part of my action research I did not take data on it. Future research could look at the type of responses parents give when there is spontaneous face to face interaction to see if parents use that time to ask questions, seek out updates on their child's progress, not at all, or use it as a time to combine questioning and to gain information.

\section{Reflection on Action Research Process}

During the process of conducting the action research I was able to learn more about my own communication practices. I rely more on indirect communication methods due to the time restraints of day to day needs of the classroom and trying to manage expectations of being a special education teacher. I found that while I thought classroom newsletters were necessary on their own, it is possible that a combination form of a weekly behavior chart and newsletter would be a better way to gain parent participation in ready items sent home. Multiple papers to look at might have been too much since many of my students have places they go after school. I would need to think of ways to make relaying information more effective for parents. I was able to gain feedback from parents that was very useful in helping me improve my daily behavior chart. Adding a smiley face key to the chart made it easier to understand. This system was also easily understood by students in the classroom. They were able to understand expectations of having behavior that they understood would give them access to positive reinforcement and choices within the classroom. I found that during the school year I had to have several meetings with parents and those conversations about various topics were easier to communicate from having the background communication. Parent's seemed more open to communicating with me and also telling me areas where I could better support them and also specific areas that they felt I was doing well. Their feedback was one of the most valuable parts of the action research as well as understanding how parent's felt about the communication methods used. Future research might want to isolate single areas to target such as indirect methods, direct methods, as well as looking at variables that pertain to the school and community that they are in. My action research took place in a community where many of the student's served at the school were considered low income. The school gives free breakfast and free lunch to all students. The area has some elevated crime rates compared to other counties in the area as well. My research mainly focused on indirect methods, how those methods were perceived by parents, and if they felt satisfied with the effort made to communicate information to them. Most parents felt satisfied with the forms of communication used. It was noted by one parent that they had no feeling either way, while another parent commented that they gave a lower score due to wanting to 
see how the rest of the year went. In the future I would like to isolate some of the variables that may influence communication and participation by parents/ guardians within a special education setting. It might be possible to combine either indirect or direct communication methods while also researching the community. By looking at how that information could be used to better inform decisions based on what communication methods would be more useful to the families being served. In all I found that communication is a key to develop and build trust with families. The first impression made by the teacher to parents/guardians is an invaluable opportunity that needs to be thought out well before students enter the classroom.

\section{Acknowledgements}

Thanks J.J.K.

\section{References}

Bartle-Haring, S., Younkin, F. L., \& Day, R. (2012). Family Distance Regulation and School Engagement in Middle-School-Aged Children. Family Relations, 61, 192-206. https://doi.org/10.1111/j.1741-3729.2011.00698.x

Colley, B. M. (2014). Voices from the Gambia: Parents' Perspectives on Their Involvement in Their Children's Education. Childhood Education, 90, 212-218. https://doi.org/10.1080/00094056.2014.910977

Henrich, C., \& Gadaire, D. (2008). Head Start and Parent Involvement. Infants and Young Children, 21, 56-69. https://doi.org/10.1097/01.IYC.0000306373.48038.e6

Karakus, M., \& Savas, A. (2012). The Effects of Parental Involvement, Trust in Parents, Trust in Students and Pupil Control Ideology on Conflict Management Strategies of Early Childhood Teachers. Kuram Ve Uygulamada Egitim Bilimleri, 12, 2977-2985.

\section{Submit or recommend next manuscript to SCIRP and we will provide best service for you:}

Accepting pre-submission inquiries through Email, Facebook, LinkedIn, Twitter, etc. A wide selection of journals (inclusive of 9 subjects, more than 200 journals) Providing 24-hour high-quality service User-friendly online submission system Fair and swift peer-review system Efficient typesetting and proofreading procedure Display of the result of downloads and visits, as well as the number of cited articles Maximum dissemination of your research work

Submit your manuscript at: http://papersubmission.scirp.org/ Or contact ce@scirp.org 